$1-1-2015$

\title{
Occupational Stress for Athletic Training Program Directors
}

Suzette Nynas

Montana State University, snynas@msubillings.edu

Carrie B. Myers

Montana State University, cbmyers@montana.edu

Follow this and additional works at: https://nsuworks.nova.edu/ijahsp

Part of the Sports Sciences Commons

\section{Recommended Citation}

Nynas S, Myers CB. Occupational Stress for Athletic Training Program Directors. The Internet Journal of Allied Health Sciences and Practice. 2015 Jan 01;13(1), Article 10.

This Manuscript is brought to you for free and open access by the College of Health Care Sciences at NSUWorks. It has been accepted for inclusion in Internet Journal of Allied Health Sciences and Practice by an authorized editor of NSUWorks. For more information, please contact nsuworks@nova.edu. 


\title{
Occupational Stress for Athletic Training Program Directors
}

\begin{abstract}
The roles and responsibilities for program directors of professional educational programs are numerous. The purpose of this study was to investigate how multiplicity of roles and responsibilities influence occupational stress. Role theory was the theoretical framework to organize the research and to investigate the influence of multiple roles and responsibilities on occupational stress of Athletic Training Program Directors (ATPDs). This mixed methods study investigated which occupational roles and responsibilities contributed to the greatest amount of occupational stress for ATPDs. All ATPDs from the Commission on Accreditation for Athletic Training Education (CAATE) accredited programs were invited to participate in an online survey to investigate personal and program characteristics and to determine which occupational roles and responsibilities produce the most occupational stress. Eighty-three ATPDs participated in this study, and the stress levels in the various occupational roles and responsibilities were measured, summed, and averaged. The results indicated that accreditation was the most stressful occupational role and responsibility category whereas service was the least stressful occupational role and responsibility category. This study presents information which heightens awareness of occupational stress experienced by ATPDs and contributes to the understanding of the multifaceted ATPD position.
\end{abstract}

\section{Author Bio(s)}

- Suzette Nynas, EdD, ATC, LAT, is an Assistant Professor and Athletic Training Program Director in the Health and Human Performance Department at Montana State University Billings, in Billings, MT.

- Carrie Myers, PhD, is an Associate Professor and Program Leader in Adult and Higher Education, in the Department of Education at Montana State University in Bozeman, MT.

\section{Acknowledgements}

The authors would like to thank and acknowledge Dr. Betsy Palmer for her contributions to this research. May she rest in peace. 


\title{
TIAHSP \\ The Internet Jousnal of Allied Health Sciences and Practice
}

Dedicated to allied health professional practice and education

Vol. 13 No. 1 ISSN 1540-580X

\section{Occupational Stress for Athletic Training Program Directors}

\author{
Suzette Nynas EdD, ATC, LAT ${ }^{1}$ \\ Carrie B. Myers PhD2
}

1. Assistant Professor and Athletic Training Program Director, Health and Human Performance Department, Montana State University Billings, Billings, MT.

2. Associate Professor and Program Leader, Adult and Higher Education, Department of Education, Montana State University, Bozeman, MT.

United States

\begin{abstract}
The roles and responsibilities for program directors of professional educational programs are numerous. The purpose of this study was to investigate how multiplicity of roles and responsibilities influence occupational stress. Role theory was the theoretical framework to organize the research and to investigate the influence of multiple roles and responsibilities on occupational stress of Athletic Training Program Directors (ATPDs). This mixed methods study investigated which occupational roles and responsibilities contributed to the greatest amount of occupational stress for ATPDs. All ATPDs from the Commission on Accreditation for Athletic Training Education (CAATE) accredited programs were invited to participate in an online survey to investigate personal and program characteristics and to determine which occupational roles and responsibilities produce the most occupational stress. Eighty-three ATPDs participated in this study, and the stress levels in the various occupational roles and responsibilities were measured, summed, and averaged. The results indicated that accreditation was the most stressful occupational role and responsibility category whereas service was the least stressful occupational role and responsibility category. This study presents information which heightens awareness of occupational stress experienced by ATPDs and contributes to the understanding of the multifaceted ATPD position.
\end{abstract}

\section{INTRODUCTION}

There has been tremendous growth and transformation in the athletic training profession and its professional education requirements over the past sixty years. One notable trend is the onset of accreditation for athletic training education programs (ATPs) in the 1970s. Only four schools had approved curriculums in the 1970s, ${ }^{1}$ whereas 370 accredited professional ATPs existed in the United States in 2012. ${ }^{2}$ Simultaneous with the evolution and growth in athletic training education, so too has the expansion of the roles and responsibilities of the athletic training program director (ATPD). ${ }^{3}$ Since the beginning of accreditation ATPDs experienced an increase in the number of roles and job responsibilities leading to an increase in overall occupational workload. ${ }^{3}$ Today, ATPDs continue to fulfill many roles and responsibilities within the ATP. Some examples of an ATPD's job duties include administrator, educator, program manager, advisor, mentor, researcher, professional in the fields, and sometimes, practicing clinician. ${ }^{3}$ In addition to the overall administration and management of the program there are also additional roles and responsibilities of scholarship and service for tenure-track or tenured ATPDs. 4,5

Occupational stress is a difficult and challenging result when personal characteristics and abilities are incongruent with the expectations, requirements, and demands of the job. 6,7 Occupational stress not only arises from personal characteristics and lack of fit but also from perceived levels of autonomy to do one's work, conflict with colleagues, meeting deadlines, and inadequate salary. ${ }^{7}$ Moreover, occupational stress results from a variety of job-related conditions such as too many obligations, too little authority, too much or too little workload, lack of support, role conflict and role ambiguity, and role overload. ${ }^{8-11}$ 
Role theory, particularly a subset of role theory called role strain, was used to guide this study. It is important to note that this particular study did not explicitly test role theory; rather, role theory was used to explain how an individual will act or is expected to interact within occupational roles and work status. ${ }^{12}$ An extremely important premise of role theory is how the equalization between multiple roles is necessary for life balance. A work-life imbalance from number of competing roles, expectations of roles, or inadequacies in particular roles can result in role strain. ${ }^{12,13}$ Thus, role strain can occur in all forms including role overload, role ambiguity, and role incongruity, and all forms of role strain can influence occupational stress and job satisfaction. ${ }^{13-16}$ Given the contemporary and numerous roles and responsibilities of ATPDs, role overload was the specific form of role strain investigated in this study.

Role overload occurs when roles are too numerous or too complex for the time and energy available. ${ }^{13}$ Role overload is common when individuals are asked to perform too many roles for which they are ill equipped to perform or cannot handle because of time and resources. ${ }^{12,13}$ Henning \& Weidner found that role overload created the largest amount of role strain for clinical preceptors (CPs). ${ }^{13}$ Additionally, in a study of nursing educators, Fong found role overload was positively correlated with burnout. ${ }^{13,17}$ It is plausible to believe both CPs and nursing educators share some similar roles and responsibilities as ATPDs including academic, advising and mentoring activities. In a study on athletic trainers, Brumels \& Beach discovered role overload had a negative effect on the athletic trainer's ideation to stay in the field of athletic training. ${ }^{15}$ Furthermore, Judd \& Perkins detailed the multiple roles required of an ATPD has led to an increase in complexity and role overload. ${ }^{3}$ Forms of role strain such as role overload have been shown to lead to less job satisfaction, increased occupational stress, decrease efficiency, and decreased dedication in the job. ${ }^{13}$

Previous research has demonstrated that ATPDs perform multiple occupational roles as part of their employment obligations. ${ }^{3-5}$ Therefore, we hypothesize that the multiple and competing occupational roles and responsibilities for ATPD can lead to role overload. Prior research has examined role strain and resultant occupational stress issues for athletic training clinicians, preceptors, and graduate students.11,13,15,18-21 However, to date, little research has specifically examined the influence of occupational roles on overall occupational stress for ATPDs. Therefore, the aim of this current study was to investigate the relationship between occupational roles and responsibilities and occupational stress levels for ATPDs.

\section{METHODS}

A survey design study22 was used to investigate the occupational stress experienced by ATPDs. After the survey was developed, piloted, and received Institutional Review Board approval, it was electronically distributed to the entire population of ATPDs in CAATE accredited ATPs. The survey was confidential and information was non-identifiable. The target population for this research was the entire population of ATPDs. Of the 367 ATPDs who were solicited, 83 individuals responded to the survey, for overall response rate of $22.6 \%$. The overall response rate for this study was comparable to the response rate (19.8\%) for other online surveys where no incentives were offered. ${ }^{23}$ The data were collected from November 22, 2011 until January 22, 2012.

The survey was comprised of four sections that addressed personal demographics and characteristics, work context, roles and responsibilities, and occupational stress. Specifically, the first section of the survey collected data including the number of years as a certified athletic trainer, number of years of service as an ATPD at their current location, the total number years of service as ATPD, number of students currently enrolled in the ATP, number of faculty and clinical staff who teach in the ATP and are part of the department, percentage of time spent within occupational roles, time spent at work, amount of support from spouse/partner, family, colleagues, and the availability and support from a mentor. The second section of the survey was developed by the researcher based on previous research and investigated the amount of occupational stress experienced by the ATPDs. ${ }^{3-5}$ In this section, twenty eight occupational roles and responsibilities for ATPDs were investigated. For each of the 28 roles and responsibilities, respondents were asked to rate their stress on a Likert scale from 1 to 4 , with 1 indicating no stress and 4 indicating great stress. The 28 roles were organized into seven occupational categories. These seven occupational role and responsibility categories were determined by combining independent variables from previous research to establish criterion and face validity of the instrument.-5 The seven categories investigated included teaching and instruction, administration, advising and mentoring, accreditation, service, and professional responsibilities, as well as other roles and responsibilities related to the job. The third section of the survey gathered demographic information such as age, gender, educational level, marital status, family status, and rank and tenure status. The last section of the survey consisted of open ended qualitative questions which addressed the perceptions of the ATPDs' professional and personal self and experiences with stress and coping strategies. Some examples of questions incorporated in the qualitative section include "Share examples of how you cope with work-related stress," "Are there any factors which influence how you experience stress?", and "Which factors influence how you cope with stress?"

(C) The Internet Journal of Allied Health Sciences and Practice, 2015 
Descriptive statistical analysis regarding the ATP information, ATPDs' personal and professional characteristics, and level of ATPDs' occupational stress were performed. The 28 occupational roles and responsibilities comprised seven occupational roles and responsibilities categories as listed in the previous paragraph. Descriptive statistics were generated for each of the seven categories. There were nine individuals who were missing one or two data points from the 28 questions on occupational stress. No systematic pattern of missing data was observed. Therefore, mean substitution was used to replace the missing data points for these nine individuals. Mean substitution maintained the accuracy of the analyses and assumed that the missing variables were related to the other variables within that category. ${ }^{24}$ Additionally, an overall occupational stress index was created from the 28 questions.

Validity analyses for the individual categories of occupational roles and responsibilities included teaching ( $\alpha=.735, \lambda=1.97)$, administrative ( $\alpha=.811, \lambda=2.88)$, advising/mentoring ( $\alpha=.770, \lambda=2.37$ ), accreditation ( $\alpha=.894, \lambda=3.06)$, service ( $\alpha=.831, \lambda=$ 2.24), professional roles and responsibilities ( $\alpha=.600=1.97$, and other roles and responsibilities ( $\alpha=.800, \lambda=2.83$ ). Estimates of reliability values as indicated by the coefficient alpha or Cronbach's alpha are suggested to be .70 or greater and is regarded as the indicator of internal validity. ${ }^{22}$ All variables except professional roles responsibilities stress were .70 or greater for this study. Factorial analysis also provided further evidence of the internal validity of each index as all the instruments demonstrated a simple structure by having all their respective items load on a single factor, and each factor exceeded the Eigen-value one criterion. ${ }^{25}$ The results for the internal reliability and validity analyses are located in Tables 1 and 2.

Table 1: Reliabilities

\begin{tabular}{|l|c|c|c|}
\hline \multicolumn{1}{|c|}{ Variable } & Cronbach's Alpha & $\begin{array}{c}\text { Cronbach's Alpha } \\
\text { Standardized Items }\end{array}$ & N of item \\
\hline Teaching Stress & .735 & .736 & 3 \\
\hline Admin Stress & .811 & .811 & 5 \\
\hline Advising Stress & .770 & .771 & 4 \\
\hline Accreditation Stress & .894 & .897 & 3 \\
\hline Service Stress & .831 & .831 & 4 \\
\hline $\begin{array}{l}\text { Prof. Responsibilities } \\
\text { Stress }\end{array}$ & .625 & .627 & 5 \\
\hline $\begin{array}{l}\text { Other Roles and } \\
\text { Responsibilities Stress }\end{array}$ & .800 & .807 & 28 \\
\hline Overall Stress & .937 & .936 & \\
\hline
\end{tabular}

Table 2: Validity

\begin{tabular}{|l|c|c|c|}
\hline \multicolumn{1}{|c|}{ Variable } & Cronbach's Alpha & Eigenvalue & N of item \\
\hline Teaching Stress & .735 & 1.97 & 3 \\
\hline Admin Stress & .811 & 2.88 & 5 \\
\hline Advising Stress & .770 & 2.37 & 4 \\
\hline Accreditation Stress & .894 & 3.06 & 3 \\
\hline Service Stress & .831 & 2.24 & 4 \\
\hline $\begin{array}{l}\text { Prof. Responsibilities } \\
\text { Stress }\end{array}$ & .625 & 1.97 & 5 \\
\hline $\begin{array}{l}\text { Other Roles and } \\
\text { Responsibilities Stress }\end{array}$ & .800 & 2.83 & 28 \\
\hline Overall Stress & .937 & & \\
\hline
\end{tabular}

Lastly open-ended survey questions regarding the ATPD's experiences with stress and coping strategies were examined. The qualitative data was analyzed and organized using open and axial coding. 26,27 This coding strategy allowed us to generate relevant and related themes about the ATPDs professional and personal identities, experiences with stress, and strategies for coping with stress. 


\section{RESULTS}

The demographic, personal and program characteristics for the ATPDs are displayed in Table 3. The results concerning institutional type were to some degree evenly distributed with a good representation from all three types of institutions denoted in this sample. The largest percentages of respondents were from baccalaureate institutions (40\%), followed by masters (32\%) and then doctorate/research (28\%).

Table 3: ATP Demographic Variables

\begin{tabular}{|c|c|c|c|c|c|}
\hline Variable & Mean & Median & SD & Minimum & Maximum \\
\hline Years Accredited & 13.27 & 10.00 & 9.76 & 3.00 & 40.00 \\
\hline Number of ATPDs & 2.33 & 2.00 & 1.38 & 1.00 & 7.00 \\
\hline $\begin{array}{l}\text { Average length of } \\
\text { Service for ATPD }\end{array}$ & 8.58 & 7.00 & 6.27 & 8.00 & 32.00 \\
\hline Total \# of Students & 36.45 & 31.00 & 22.76 & 2.00 & 133.00 \\
\hline Male & 14.15 & 12.00 & 9.11 & 5.00 & 51.00 \\
\hline Female & 22.30 & 18.00 & 15.10 & 1.00 & 13.00 \\
\hline $\begin{array}{c}\text { Total \# of Teachers } \\
\text { ATP }\end{array}$ & 6.51 & 7.00 & 2.50 & 0.00 & 8.00 \\
\hline Male & 3.27 & 3.00 & 1.63 & 0.00 & 7.00 \\
\hline Female & 3.24 & 3.00 & 1.73 & 1.00 & 47.00 \\
\hline $\begin{array}{c}\text { Total Faculty } \\
\text { Department }\end{array}$ & 12.01 & 9.00 & 10.27 & & \\
\hline Male & 6.05 & 4.00 & 5.42 & 6.00 & 22.00 \\
\hline Female & 5.89 & 4.00 & 11.08 & 5.00 & 40.00 \\
\hline Total \# of CPs & 19.45 & 16.50 & 5.99 & 0.00 & 60.00 \\
\hline Male & 9.90 & 8.00 & 5.19 & 0.00 & 31.00 \\
\hline Female & 8.56 & 7.00 & & & 21.00 \\
\hline
\end{tabular}

Data was also collected regarding the ATPD. Please see Tables 4 and 5 for summary of descriptive statistics for the ATPD.

Table 4 ATP Director Characteristics (part 1)

\begin{tabular}{|l|c|c|c|c|c|}
\hline \multicolumn{1}{|c|}{ Variable } & Mean & Median & SD & Minimum & Maximum \\
\hline Years Certified & 19.60 & 19.00 & 8.18 & 6.00 & 37.00 \\
\hline Years Current Director & 7.41 & 6.00 & 6.94 & 1.00 & 33.00 \\
\hline $\begin{array}{l}\text { Years Total as } \\
\text { Director }\end{array}$ & 9.00 & 7.00 & 7.84 & 1.00 & 38.00 \\
\hline $\begin{array}{l}\text { \% Of Time Spent in } \\
\text { Role }\end{array}$ & & & & & \\
\hline \multicolumn{1}{|c|}{$\%$ Administration } & 23.11 & 25.00 & 8.92 & 5.00 & 50.00 \\
\hline \multicolumn{1}{|c|}{ \%Teach } & 46.80 & 50.00 & 15.63 & 12.50 & 75.00 \\
\hline \multicolumn{1}{|c|}{ \%Advising/Mentor } & 10.82 & 10.00 & 6.43 & 0.00 & 30.00 \\
\hline \multicolumn{1}{c|}{$\%$ \%Service } & 5.98 & 5.00 & 8.10 & 0.00 & 40.00 \\
\hline Hours Per Week Total & 8.24 & 9.00 & 4.93 & 0.00 & 20.00 \\
\hline Age & 7.46 & 0.00 & 11.42 & 0.00 & 45.00 \\
\hline Number of children & 31.53 & 32.75 & 18.93 & 2.00 & 100.00 \\
\hline $\begin{array}{l}\text { Number of children at } \\
\text { home }\end{array}$ & 1.2 .05 & 42.00 & 8.64 & 29.00 & 62.00 \\
\hline
\end{tabular}


Table 5 ATPD Characteristics (part 2)

\begin{tabular}{|c|c|c|}
\hline Variable & Frequency & Percent \\
\hline Mender & & 53.3 \\
\hline Memale & 40 & 46.7 \\
\hline Educational Level & 35 & 26.7 \\
\hline Masters & 20 & 0.0 \\
\hline Working towards second Masters & 0 & 18.7 \\
\hline Working towards terminal & 14 & 54.7 \\
\hline Terminal & 41 & \\
\hline Marital Status & & 86.7 \\
\hline Married and Partnered & 65 & 13.4 \\
\hline Other (single, divorced, separated) & 10 & 16.0 \\
\hline Rank & & 22.7 \\
\hline Instructor & 12 & 38.7 \\
\hline Assistant Professor & 17 & 9.3 \\
\hline Associate Professor & 29 & 13.3 \\
\hline Professor & 7 & \\
\hline Other & 10 & 41.3 \\
\hline Tenure Status & 31 & 20.0 \\
\hline Non Tenure & 15 & 38.7 \\
\hline Tenure Track, Working Toward & & \\
\hline Tenure & 29 & \\
\hline Tenured & & \\
\hline & & \\
\hline
\end{tabular}

Table 6 presents the results for the seven different categories of occupational stressors experienced by ATPDs. These categories included teaching, administration, advising/mentoring, accreditation, service, professional responsibilities. And other roles and responsibilities. Of important note, the highest scores in the accreditation (16/16) and administration (20/20) categories reached the maximum score for that category. Additionally the highest scores in the professional roles (15/16) and other roles and responsibilities (19/20) categories reached near maximum score for the respected categories.

\begin{tabular}{|c|c|c|c|c|c|}
\hline Variable & Mean & Median & SD & Minimum & Maximum \\
\hline Teaching and Instruction & 6.43 & 6.00 & 1.93 & 3.00 & $10.00 a$ \\
\hline Administration & 11.93 & 12.00 & 3.46 & 5.00 & $20.00 \mathrm{~b}$ \\
\hline Advising and Mentoring & 8.29 & 8.00 & 2.40 & 4.00 & $13.00 \mathrm{c}$ \\
\hline Accreditation & 11.43 & 12.00 & 2.79 & 4.00 & $16.00 \mathrm{~d}$ \\
\hline Service & 5.03 & 5.00 & 1.87 & 2.00 & $9.00 \mathrm{e}$ \\
\hline $\begin{array}{l}\text { Professional } \\
\text { Responsibilities }\end{array}$ & 8.29 & 9.00 & 3.83 & 1.00 & $15.00 \mathrm{f}$ \\
\hline $\begin{array}{l}\text { Other Roles and } \\
\text { Responsibilities }\end{array}$ & 13.31 & 14.00 & 3.05 & 5.00 & $19.00 \mathrm{~g}$ \\
\hline Overall Occupational Stress & 64.70 & 65.00 & 11.99 & 37.00 & $91.00 \mathrm{~h}$ \\
\hline
\end{tabular}

Further analysis presents a standardized metric in which to order the occupational stress measures in terms of the most-to-least stressful (See Table 7). This metric is presented as a percentage, which calculates the extent to which the mean value for each stress measure approaches its empirical maximum. This is accomplished through the following equation: (mean/maximum) $x$ 100. In interpreting the values in Table 7, it is important that the values represent relative stress levels when compared to each other, and most importantly, the overall stress measure. For the overall stress measure, the mean value of 64.70 is at $58 \%$ of its empirical maximum value of 112 . Therefore, for the individual measures of stress, values below $58 \%$ are less than the average 
for the overall stress measure (where lower $\%=$ lower relative stress levels), and those above $58 \%$ are more than the average for the overall stress measure (where higher $\%=$ higher relative stress levels). By using this metric and comparison to the average overall stress, this study identified which specific roles contributed relatively more or less stress to an ATPD's overall occupational stress.

As indicated in Table 7, three occupational role and responsibility categories have relatively high values, representing greaterthan-average stress. The greatest of these is stress from accreditation with a mean value that is $71 \%$ of its possible maximum. Following this is stress from other roles and responsibilities at $67 \%$ and stress from administration at $60 \%$. The domains that appear to produce the least occupational stress were from advising and mentoring, and professional responsibilities both at $52 \%$ and service at $42 \%$. It is interesting to note the almost 30 percentage point differential between occupational stressors from accreditation (71\%) and service (42\%). This difference indicates that accreditation is the role which creates the highest relative occupational stress level for most ATPDs whereas as service is the least stressful role.

\section{Table 7. Percentage of Occupational Stress}

\begin{tabular}{|l|l|}
\hline \multicolumn{1}{|c|}{ Variable } & Mean As Percent of Empirical Maximum \\
\hline Accreditation & $71 \%$ \\
\hline Other Roles and Responsibilities & $67 \%$ \\
\hline Administration & $60 \%$ \\
\hline OVERALL OCCUPATIONAL STRESS & $58 \%$ \\
\hline Teaching and Instruction & $54 \%$ \\
\hline Advising and Mentoring & $52 \%$ \\
\hline Professional Responsibilities & $52 \%$ \\
\hline Service & $42 \%$ \\
\hline
\end{tabular}

The qualitative data and generated themes were used to better understand and contextualize the quantitative results. The openended survey questions addressed perceptions of the ATPDs' professional and personal characteristics, experiences with stress, and strategies for coping with work-related stress. The first theme was generated from the open-ended question for how the ATPD respondents cope with work-related stress. One of the major ways for coping with work related stress was exercise. Over half of those who responded $(\mathrm{N}=36)$ stated that exercise helps them cope with stress. Other themes for coping with stress included spending time with family, talking with support networks, hobbies (reading, music, games), good time management, setting goals and priorities, maintaining faith, perspective and a positive attitude, and setting limits on work (i.e. not taking work home, leaving campus for lunch).

The next open-ended question asked about factors that contribute to work-related stress. The themes for this question were more diverse but some of the more commonly occurring themes included interactions with others creating stress (i.e. lack of understanding, support, respect, others moods and stress levels), personality, time of year, faith, emotional and physical fatigue, past experiences, complexity of position, number of stressors, and other time commitments outside of work. When participants were asked to reflect upon which factors influenced how one copes with stress, numerous respondents replied with similar factors on how he or she experiences stress. Some of the themes included faith, perspective, attitude and personality, sleep, time commitments for work and personal life, and the availability of a support network (friends, significant other, colleagues, and administration). One interesting finding is that a number of ATPDs identified common factors for both what contributed to stress and ways of coping with stress (e.g., family, faith, personality) suggesting that a number of factors can be stress inducers and stress reducers.

\section{DISCUSSION}

The results of this study revealed certain categories of occupational roles and responsibilities disproportionately contributed to the occupational stress experienced by ATPDs. The most important finding from this study was the influence of accreditation (CAATE administration, maintaining accreditation, implementing standards and deadlines) on the perceived level of stress of the ATPD. When comparing the stress experienced in the variety of occupational role and responsibility categories, by in large, accreditation provoked the most stress -- almost 30\% more than lowest stressful occupational role and responsibility category of service. This finding is significant for two reasons. One, ATP accreditation plays a large and important role in the lives of ATPDs. Two, there may be limited resources and support available to assist ATPDs with accreditation and the increase in workload as a result of accreditation and related administrative duties. ${ }^{3}$ Therefore, interventions which could be mobilized at the individual, institutional, or accrediting agency levels to decrease the amount of stress with regard to accreditation may provide an important way to reduce the work-related stress related to accreditation.

(C) The Internet Journal of Allied Health Sciences and Practice, 2015 
Another important finding is that other roles and responsibilities (overall workload, performing tasks not related to ATP, salary and benefits, resources, and time away from personal and family time) and administration (curriculum development, recruiting, program assessment) categories also disproportionately contributed to the occupational stress of ATPDs. These findings are similar to the results in a study conducted by Judd \& Perkins where they queried ATPDs about the least beneficial and least satisfying aspects of their jobs. ${ }^{3}$ These researchers revealed that many ATPDs believed the least beneficial and least satisfying aspects of their jobs included too many roles and responsibilities, program management and administration, accreditation, decreased personal time, professional expectations of rank and tenure, and student related issues. ${ }^{3}$ Another important finding is the differential influence of the various roles and responsibilities on stress. Notably, ATPDs experienced more stress from some occupational categories (accreditation, other roles and responsibilities, administration) than from others (teaching and instruction, advising and mentoring, professional responsibilities, and service). Yet despite the high levels of stress reported by some ATPDs, the findings also reveal important ways that ATPDs have learned to cope with the work-related stress (e.g., exercise and support networks).

An additional finding from this study was the median length of service for an ATPD was only seven years, and the mean length of service was nine years. This length of ATPD service finding is further supported by other studies. Perkins \& Judd reported the median number of years an ATPD served was seven and one-half in 1988 and nine years in $2000 .{ }^{5}$ Results from this study along with previous studies indicate the lengths of most ATPDs' careers are typically between seven and one-half to nine years of service. Thus ATPDs are not spending the majority of their professional lives in a program director role and maybe not becoming proficient in their ATPDs skills before moving on to a different career. In 2004, Judd \& Perkins discovered that many ATPDs left their job as a result of failing to achieve tenure, ineffectiveness as an ATPD, family responsibilities, program issues, or to change employment (clinical practice or career advancement). ${ }^{3}$

There are several limitations to these findings. First, this study relied on self-reported data, which can be influenced by personal biases and individual experiences and may limit the generalizability of the study. External validity may be further limited by the low response rate of the survey. Lastly, part of the survey was developed by the researchers and did not have extensive psychometric testing prior to implementation. These limitations and the findings of this study lead to recommendations for further research. One area for further investigation is to investigate why the median years of service for ATPDs is between seven and one-half to nine years. Why are ATPDs leaving their jobs after less than ten years of service? Conceivably ATPDs could be leaving their jobs because the accreditation, other roles and responsibilities, and administration occupational roles and responsibility categories disproportionately weigh heavier on the ATPD? Perhaps roles and responsibilities associated with accreditation are too numerous, too complex or too ambiguous? ${ }^{14,15}$ Maybe release time and length of contracts are the issues. ${ }^{3}$ Imaginably those ATPDs who have nine month contracts or have less release time for administrative and other duties could have more occupational stress as result of decreased time dedicated to accreditation and administration of the ATP. Another interesting line of inquiry would be person-job-fit.7 For example, how well do the ATPDs' personality and skills match the different roles and responsibilities of the job (e.g., accreditation)? Moreover, a different line of inquiry could address how institutions and programs could better support the accreditation process for these individuals. An additional suggestion for future research would be the investigation of the relationship between job satisfaction and occupational stress. A study by Gellis demonstrated a relationship between stress and job satisfaction. ${ }^{28} \mathrm{He}$ discovered that as stress increased, job satisfaction decreased. Thus, a follow up to study could investigate the relationship between stress and job satisfaction for ATPDs. Lastly, it would be noteworthy to compare the occupational stress between program directors for professional athletic training programs to determine if there is a difference in occupational stress between program directors at the bachelors and the master's levels.

\section{CONCLUSION}

This current study contributes to the literature and the further understanding the relationships between the multiplicity of ATPD occupation and work-related stress. It was the aim of this study to investigate the amount occupational stress experienced by ATPDs and to understand how the different roles and responsibilities contribute to this work-related stress. The results from this study indicated that ATPDs experienced disproportionate amounts of occupational stress from accreditation, other roles and responsibilities, and administration, with these responsibilities contributing to the largest amounts of occupational stress. Out of all the roles and responsibilities required of the ATPD position, accreditation contributed to the highest levels of perceived stress -- almost 30\% more stress than the least stressful occupational category, service. Since accreditation is such a crucial aspect of professional athletic training education future studies will need to investigate why accreditation contributes such a disproportionate amount of stress to the ATPD position as well as to determine strategies to better and less stressfully navigate the accreditation job responsibilities. Perhaps ATPDs need mentoring and more focused training to overcome obstacles which lead to occupational stress. ${ }^{17} \mathrm{An}$ investigation to determine reasons ATPDs leave their position prior to the ten year mark would also be interesting and helpful to reduce the attrition rate for ATPDs.

(C) The Internet Journal of Allied Health Sciences and Practice, 2015 


\section{ACKNOWLEDGEMENTS}

The authors would like to thank and acknowledge Dr. Betsy Palmer for her contributions to this research. May she rest in peace.

\section{REFERENCES}

1. Ebel RG. Far Beyond the Shoe Box: Fifty Years of the National Athletic Trainer's Association. New York: Forbes; 1999.

2. Commission on Accreditation of Athletic Training Education (CAATE). Accredited programs. http://caate.net/find-programs/. Accessed October 29, 2014.

3. Judd MR, Perkins SA. Athletic training education program directors' perception on job selection, job satisfaction, and attrition. J Athl Train. 2004;39(2):185-92. [PMID 15173871]

4. Walter JM, Van Lunen BL, Walker SE, Ismaeli ZC, Onate JA. An assessment of burnout in undergraduate athletic training education program directors. J Athl Train, 2009;44(2):190-6. [PMID 12937482]

5. Perkins SA, Judd MR. Dilemmas of program directors: Then and now. J Athl Train. 2001;36(4):396-400. [PMID 12937482]

6. Vagg PR, Speilberger CD, Wasala CF. Effects of organizational level and gender on stress in the workplace. Int J Stress Manag. 2002;9(4):243-61.

7. Speilberger CD, Reheiser EC. The job stress survey: Measuring gender differences in occupational stress. J Soc Behav Pers. 1994;9(2):199-218.

8. Burke R. Occupational stresses and job satisfaction. J Soc Psychol. 1976;100:235-44.

9. Shultz KS, Wang M, Olson DA. Role overload and underload in relation to occupational stress and health. Stress Health. 2009;26:99-111.

10. Michael G, Anastasios S, Helen K, Catherine K, Christine K. Gender differences in experiencing occupational stress: The role of age, education and marital status. Stress Health. 2009;25:397-404.

11. McLaine AJ. An overview of burnout in athletic trainers. Athl Ther Today. 2005;10(6):11-3.

12. Turner JH. Role theory. In: Turner JH, ed. Handbook of Sociological Theory: New York, NY: Kluwer Academic/Plenum Publishers; 2001:233-54.

13. Henning JM, Weidner TG. Role strain in collegiate athletic training approved clinical instructors. J Athl Train. 2008;43(2):275-83. [PMID 18523564]

14. Aziz M. Organizational role stress: an investigation of gender differences. Stud Psychol. 2007;49(1):53-61.

15. Brumels K, Beach A. Professional role complexity and job satisfaction of collegiate certified athletic trainers. J Athl Train. 2008;43(4):373-8. [PMID 18668170]

16. Wolverton M, Wolverton ML, Gmelch WH. The impact of role conflict and ambiguity on academic deans. J Higher Educ. 1999;70(1):80-106.

17. Fong C. Role overload, social support, and burnout among nursing educators. J Nurs Educ.1990;29(3):102-8.

18. Giacobbi PR. Low burnout and high engagement levels in athletic trainers: Results of a nationwide random sample. $J$ Athl Train. 2009;44(4):370-7. [PMID 19593419]

19. Hendrix $A E$, Acevedo EO, Hebert $E$. An examination of stress and burnout in certified athletic trainers at division I-A universities. J Athl Train. 2000;35(2):139-44. [PMID 16558622]

20. Kania ML, Meyer BB, Ebersole KT. Personal and environmental characteristics predicting burnout among certified athletic trainers at National Collegiate Athletic Association institutions. J Athl Train. 2009;44(1):58-66. [PMID 19180220]

21. Reed S. The stress and coping response of certified graduate athletic training students. J Athl Train. 2004;39(2):193-200. [PMID 15173872]

22. Johnson B, Christensen L. Educational Research: Quantitative, Qualitative, and Mixed Approaches. Los Angeles, CA: Sage;2012.

23. Sax LJ, Gilmartin SK, Bryant AN. Assessing response rates and nonresponse bias in web and paper surveys. Res High Educ. 2003;44(4):409-32.

24. Downey R, King C. Missing data in Likert ratings: a comparison of replacement methods. J Gen Psychol. 1998; 125(2):17591. [PMID 9935342]

25. Revelle W, Rocklin T. Very simple structure: An alternative procedure for estimating the optimal number of interpretable factors. Multivariate Behav Res. 1979;14(4):403-14.

26. Cresswell JW. Qualitative Inquiry \& Research Design. Thousand Oaks, CA: Sage; 2013.

27. Straus A, Corbin J. Basics of Qualitative Research: Grounded Theory Procedures and Techniques. Newbury Park, CA: Sage; 1990.

28. Gellis Z. Coping with occupational stress in healthcare: A comparison of social workers and nurses. Admin Soc Work. 2002;26(3):37-52. 